\section{Head trauma: A significant public health concern among young men in Botswana. Etiology referral patterns and opportunities for interventions}

\author{
Megan Cox, ${ }^{1}$ Timothy Becker, ${ }^{2}$ \\ Mpapho Motsumi ${ }^{3}$ \\ ${ }^{1}$ Department of Emergency Medicine, \\ Faculty of Medicine, University of \\ Botswana, Gaborone, Botswana; \\ ${ }^{2}$ Perelman School of Medicine, \\ University of Pennsylvania, USA; \\ ${ }^{3}$ Department of Surgery, Faculty of \\ Medicine, University of Botswana, \\ Gaborone, Botswana
}

\begin{abstract}
This study aims to present and discuss acute Head Injury (HI) presentations including etiology, referral patterns and disposition in patients presenting to a major referral hospital in Gaborone, Botswana. Cross-sectional, retrospective data collection from July 2015 through September 2015 extracted descriptions of patient demographics, mechanism of injury, comorbidities, diagnosis and disposition from Emergency Centre (EC) records. $360 \mathrm{HI}$ patients presented in three months, averaging four per day and increasing on weekends and end of the month. HI disproportionately impacted young adult males, with motor vehicle accidents accounting for 38\%, violence implicated in 39\% and $80 \%$ recorded as blunt trauma. HIV status was unknown for $84 \%$ of patients at the time of presentation and $10 \%$ of patients were recorded as HIV positive. Patients referred from external hospitals had a higher admission rate. $\mathrm{HI}$ in young males is a significant trauma burden in this hospital, similar to the known regional trauma patterns. More studies regarding trauma, alcohol, and violence related to paydays should be considered to investigate and reduce the burden of $\mathrm{HI}$ in Botswana.
\end{abstract}

\section{Introduction}

Trauma has emerged as one of the greatest public health challenges of the early $21^{\text {st }}$ century. An estimated 5.8 million people die annually from injuries, more than from malaria, tuberculosis, and HIV/AIDS combined. ${ }^{1,2}$ Traumatic Brain Injury (TBI) is the most common cause of death and disability in trauma, especially in young adults. The incidence of TBI in Sub-
Saharan Africa is $150-170$ per 100,000 compared to the global average of 106 per $100,000 .^{3}$

Trauma victims in low- and middleincome countries (LMIC) suffer greater morbidity and mortality than their counterparts in high-income countries, thus highlighting trauma surveillance and care improvement as a potentially powerful means to reduce global health disparities. ${ }^{4,5}$ Although the impact of trauma has been widely acknowledged, few studies have described the prevalence and etiology of trauma in developing regions. ${ }^{4,6}$ Since causes and outcomes of trauma vary considerably among countries, local data is critical to developing effective treatment and prevention strategies. Increased urbanization and motor vehicle use partly underlie the rise of traumatic burden in the developing world. The burden of motor vehicle accidents (MVAs) tends to increase with development in LMICs, uniquely placing countries with recognized rapid development, such as Botswana, at greater risk. ${ }^{7}$ Little research exists regarding the trauma burden in Botswana, an upper middle income country in Southern Africa.

Princess Marina Hospital (PMH), located in Gaborone, the capital and largest city in Botswana, with a population greater than 230,000 serves as the main teaching and referral hospital for the country and is the primary and district referral hospital for local residents. ${ }^{8}$ A study of presentations to the PMH EC in 2011 found that trauma accounted for 22.3 percent of all patient encounters, trailing only infections $(25.6 \%)$, and vastly surpassing obstetric and gynecologic conditions (12.9\%), non-communicable diseases $(12.6 \%)$, and GI disorders $(8.4 \%) .{ }^{9}$ However this 2011 study did not assess etiologies of trauma presentations, and there is no current trauma registry at PMH. HI is a known significant worldwide trauma burden so it was chosen to be studied to better characterize and describe demographics, referral patterns, aetiologies, diagnosis, co-morbidities and disposition of trauma patients presenting to $\mathrm{PMH}$.

\section{Study Site}

Data was collected retrospectively on all patients with HI who presented to the PMH EC from July 1, 2015 through September 30, 2015. PMH is a 567-bed facility with a 24-hour EC and all medical, paediatric, obstetric, and surgical specialties including a mixed (adult and children) 8bed ICU. PMH is one of only two public facilities in the country to offer CT scanning services, so trauma patients from much of the country are referred to $\mathrm{PMH}$ for further evaluation.
Correspondence: Megan Cox, Emergency Department, Faculty of Medicine, Private bag 00713, University of Botswana, Gaborone, Botswana.

Tel.: +26776574766

E-mail: Mcox2050@gmail.com

Key words: Head injury; assault; Botswana; trauma; MVA.

Contributions: $\mathrm{MC}$ and TB designed the study, performed data entry and drafted the article. MM assisted with data analysis and editing the article. All three authors approved the final draft.

Conferences: a section of this article was presented in abstract form as a poster at the International Conference of Emergency Medicine in Capetown, South Africa in April 2016.

Received for publication: 14 October 2017. Accepted for publication: 26 February 2018.

This work is licensed under a Creative Commons Attribution NonCommercial 4.0 License (CC BY-NC 4.0).

(C) Copyright M. Cox et al., 2018

Licensee PAGEPress, Italy

Journal of Public Health in Africa 2018; 9:798 doi:10.4081/jphia.2018.798

\section{Materials and Methods}

A database (Microsoft Access 2010) was setup on a computer in the EC at the beginning of July 2015 and was used to extract relevant information from EC patient records. Data was entered into the database by a research assistant, a limited number of doctors working in the EC, and an Emergency Medicine (EM) specialist. Several training meetings were held for all study members involved with data entry.

Information was collected directly from the PMH triage sheet and PMH EC records describing patient demographics (e.g., age, sex, geographical location), presentation (e.g., method of presentation to EC, time of injury), mechanism of injury, referring institution, disposition and co-morbidities. Physician descriptions of the nature of specific injuries written on EC records were coded according to WHO International Classification of External Causes of Injury (ICECI) categories on four axes, intent, mechanism, object producing injury, and alcohol use, at time of data entry. ${ }^{10} \mathrm{Co}-$ morbidities (hypertension, diabetes, pregnancy, psychiatric conditions, and HIV status) and the EC diagnosis relevant to HI were noted from the EC record, along with the patient's 
destination and discharge disposition from EC. Diagnosis was based only on the treating doctors' notes written in the EC record.

\section{Participants}

Triage forms for all patients who presented to the EC during the study period were reviewed. Patients presenting with any injury to the head were included. Patients who were brought in dead were excluded. Ethics committees at the University of Botswana, University of Pennsylvania, Princess Marina Hospital, and Botswana Ministry of Health approved study procedures.

\section{Results}

\section{Demographics}

During the study period, 360 patients were identified as presenting with HI. HI patients included 247 (68.6\%) males and $113(31.3 \%)$ females. Patients had a mean age of $29.4(\mathrm{SD}=16.1$, range 1 to 90$)$ and median age of 29.5. In our setting, patients over the age of 13 years are admitted to adult wards, therefore $299(83.1 \%)$ were listed as adults, $57(15.8 \%)$ were paediatric patients, and 4 patients had missing age data. Eighty percent $(80 \%)$ of patients presenting with $\mathrm{HI}$ were younger than 40 years.

\section{Etiology}

The majority of HI was documented as unintentional or accidental in origin (59\%), but $\mathrm{HI}$ attributable to assault constituted $39 \%$ of the total presentations. Table 1 displays the classification of injury causes.

MVAs accounted for $136(65 \%)$ of unintentional HI, followed by falling, jumping, or being pushed $52(24.8 \%)$, and other blunt forces $20(9.5 \%)$. Blunt force, including rods, bottles, and stones, was the primary mechanism of head trauma due to assault $85(59.9 \%)$, followed by other penetrating forces $21(14.8 \%)$, and cuts and stabbings $10(7.0 \%)$. Males outnumbered females in all causes of injury. Figure 1 shows the injury intent stratified by age.

\section{Comorbidities}

The EC record indicated the HIV status as unknown (or undocumented) in $84 \%$ of the HI presentations; $10 \%$ of patients were HIV positive and $6 \%$ were believed to be negative. Alcohol involvement in $\mathrm{HI}$ patients was poorly documented with 278 patients $(77.2 \%)$ having no information about alcohol recorded in their EC record and only 37 patient records (10.3\%) implicated alcohol in the event. 16 EC presentations specifically recorded no suspicion of alcohol use. EC records were noted to have poor documentation concerning other comorbidities.

\section{Referral patterns}

Patients presented to PMH EC from throughout Botswana for management of HI (Figure 2), with origin recorded for 318 of $360(88.3 \%)$ of patients. Of those with

Table 1. Mechanisms of head injuries.

\begin{tabular}{|c|c|c|c|c|c|c|}
\hline \multirow[b]{2}{*}{ MVA overall } & & \multicolumn{2}{|c|}{ Unintentional Assault } & \multirow[t]{2}{*}{ Unknown } & \multirow{2}{*}{$\begin{array}{ll}\text { Total } & \\
& 138\end{array}$} & \multirow{2}{*}{\begin{tabular}{|r} 
Percentage of total \\
$38.3 \%$
\end{tabular}} \\
\hline & & 137 & 1 & & & \\
\hline \multirow[t]{3}{*}{ MVA stratification: } & : occupant & 55 & & & 55 & $15.3 \%$ \\
\hline & pedestrian & 40 & 1 & & 41 & $11.4 \%$ \\
\hline & unspecified & 42 & & & 42 & $11.7 \%$ \\
\hline \multicolumn{2}{|c|}{ Other transportation } & 1 & & & 1 & $0.3 \%$ \\
\hline \multicolumn{2}{|c|}{ Falling, jumping, or pushed } & 52 & 2 & & 54 & $15.0 \%$ \\
\hline \multicolumn{2}{|c|}{ Other specified or unspecified blunt } & 20 & 85 & 2 & 107 & $29.7 \%$ \\
\hline Shot by firearm & & 0 & 0 & 1 & 1 & $0.3 \%$ \\
\hline Cut or stabbed & & 0 & 10 & & 10 & $2.8 \%$ \\
\hline \multicolumn{2}{|c|}{ Other penetrating force } & o & 21 & & 21 & $5.8 \%$ \\
\hline Other & & 0 & 2 & & 2 & $0.6 \%$ \\
\hline \multirow[t]{2}{*}{ Unspecified } & & 0 & 21 & 5 & 26 & $7.2 \%$ \\
\hline & & 210 & 142 & 8 & 360 & \\
\hline
\end{tabular}

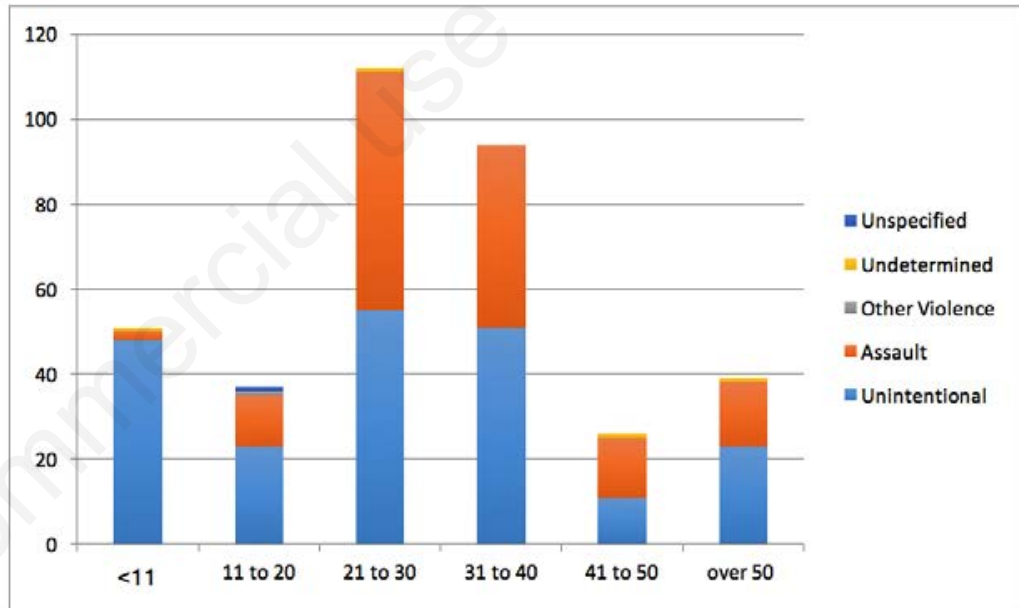

Figure 1. HI intent of injury by age.

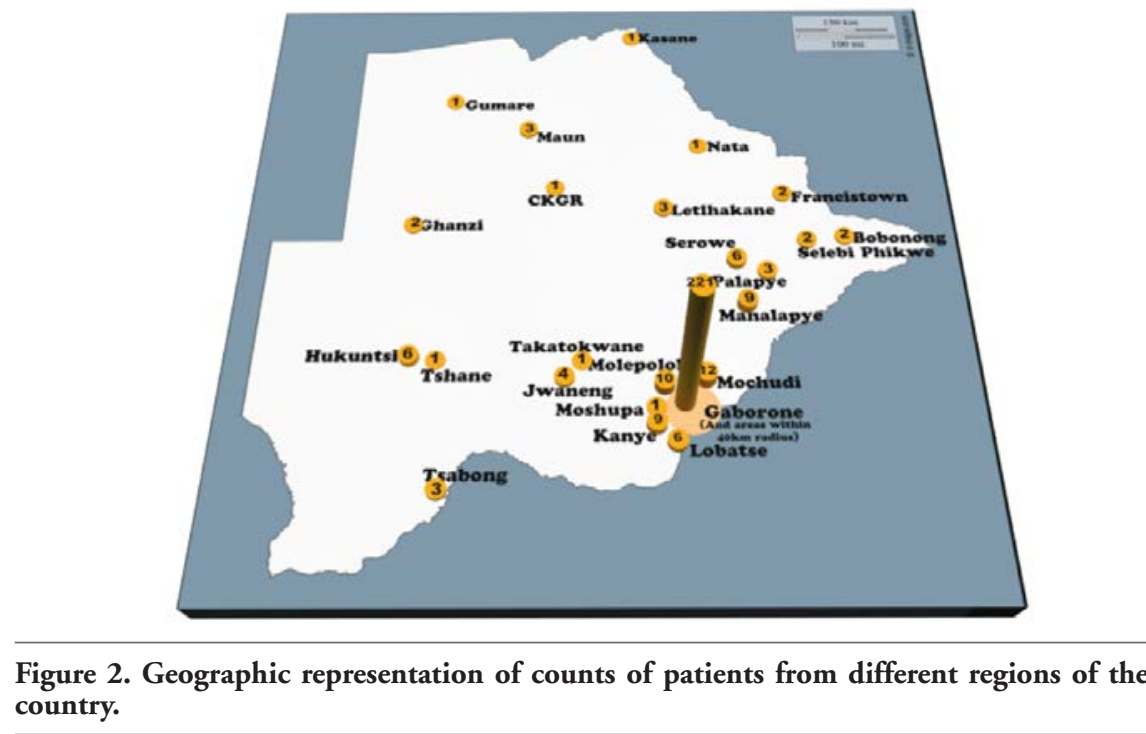

Figure 2. Geographic representation of counts of patients from different regions of the country. known geographical origin, $69.5 \%$ presented to PMH EC from within $40 \mathrm{~km}$ of Gaborone. The farthest patient origin was from a health facility (Gumare) over $1000 \mathrm{~km}$ from PMH. Patients were referred from various other care settings, most commonly transfers from other public (district

\section{recis}


or primary) hospital facilities $(36.1 \%)$, followed by referrals from local Gaborone clinics $(33.1 \%)$, EMS from site of injury $(14.4 \%)$, and patient self-referrals (12.5\%).

$\mathrm{HI}$ presented to the EC more frequently on the weekend days (Figure 3).

Wages are paid once a month in Botswana and usually at the end of the month. This period after pay day referred to as month end, anecdotally is known in the EC for increased presentations of trauma. Looking at the data, this period was defined by the authors as the last 6 days of one month and the first day of the next month. At this month end period there was an average of 4.75 injuries per day, whereas at other times it was 3.3 injuries per day; but these figures were not statistically significant.

\section{Disposition}

Overall $197(55 \%)$ of the $360 \mathrm{HI}$ patients were discharged from the EC and $96(27 \%)$ were admitted to an inpatient ward, $33(9 \%)$ transferred to external hospitals, $11(3 \%)$ sent to PMH operation theatre, and $10(3 \%)$ admitted to PMH ICU. Table 2 shows the disposition of patients stratified by sex.

Of the 197 discharged patients, 168 $(85 \%)$ were referred to PMH EC from within a $100 \mathrm{~km}$ radius. The disposition of the patient varied depending on the patient's referral pattern with $85 \%$ of self-referred patients and $74 \%$ referrals from local Gaborone clinics discharged directly home from the EC. Patients transported by the EMS were discharged home $70 \%$ of the time however patients transferred from other hospitals were most likely to be admitted. Only 30 of these 102 transferred patients $(29.4 \%)$ were discharged, while the remaining 72 were admitted to medical or surgical ward $(60,58.8 \%)$, ICU $(6,5.9 \%)$ or operating theater $(5,4.9 \%)$

\section{Discussion}

\section{Assessment of results and Implications}

This is the first study from Botswana reporting etiology, referral patterns and disposition of acute head injuries. The findings are similar to the worldwide and SSA burden of HI with head trauma disproportionately affecting young adult males. The majority of head trauma was unintentional, with MVAs the most common cause but assaults, most frequently by blunt force was the most common single cause. Men were more likely to be admitted and undergo surgical interventions than women, suggesting more severe injuries.

Local acute trauma data to compare with is scarce; but a recent study of spinal injuries in Botswana reported the most common spinal injury aetiology was MVA; especially in the 31-45 years age group and assault was the second. ${ }^{11}$ A recent study from Botswana also showed that the country's significant positive economic growth was associated with an increased number of vehicles per 1000 population and increased MVA fatalities. ${ }^{7}$

Alcohol was only implicated in this study as contributing to $10 \%$ of $\mathrm{HI}$, but was not widely documented in the PMH EC record. Alcohol is a known risk factor for MVAs and violence, and thus TBI, especially in LMICs. ${ }^{12}$ Trauma surveillance data from a major trauma hospital in neighboring South Africa recently reported over $80 \%$ of emergency patients with intentional injuries were under the influence of alcohol or other intoxicating substances. ${ }^{13}$ Significant reductions in traffic accidents were seen after an increased alcohol levy in Botswana, ${ }^{14}$ but there is currently no mandatory alcohol testing of traffic related presentations to health centres in Botswana.

The primary mechanism of $\mathrm{HI}$ was assault at $60 \%$, in young males, with injury presentations increasing in the week around payday. Despite this result not being statistically significant in this small study, this effect has been noted in other LMICs. A recent study in Guatemala found a cyclic time trend in violence related deaths and

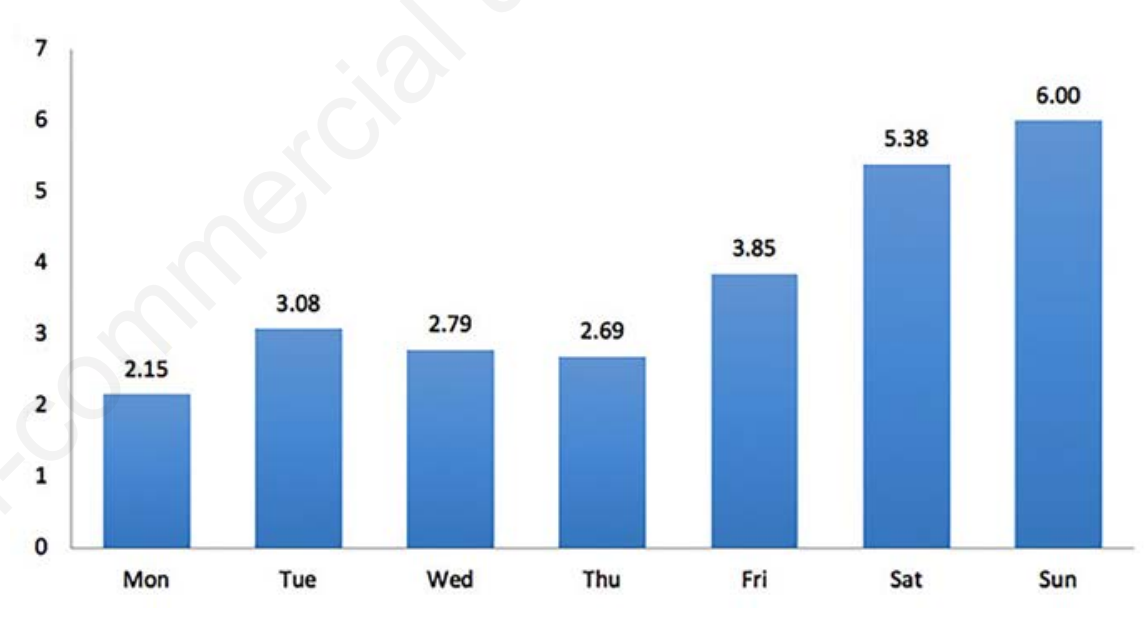

Figure 3. Average frequency of head injuries by day of the week.

Table 2. Disposition by sex.

\begin{tabular}{|c|c|c|c|c|c|c|}
\hline & $\begin{array}{c}\text { Men } \\
\text { Frequency }\end{array}$ & $\%$ of men & $\begin{array}{l}\text { Women } \\
\text { Frequency }\end{array}$ & $\%$ of women & $\begin{array}{c}\text { Total } \\
\text { Frequency }\end{array}$ & $\%$ of total \\
\hline Admit to ICU & 9 & 3.70 & 1 & 0.85 & 10 & 2.8 \\
\hline Admit to Ward & 76 & 31.28 & 20 & 17.09 & 96 & 26.7 \\
\hline Admit to Operating Theater & 9 & 3.70 & 2 & 1.71 & 11 & 3.1 \\
\hline Discharge home & 120 & 49.38 & 77 & 65.81 & 197 & 54.7 \\
\hline Died in EC & 1 & 0.41 & 0 & 0.0 & 1 & 0.3 \\
\hline Left without being seen & 1 & 0.41 & 0 & 0.0 & 1 & 0.3 \\
\hline Self-discharge AMA & 4 & 1.65 & 0 & 0.0 & 4 & 1.1 \\
\hline Transfer to external hospital & 21 & 8.64 & 12 & 10.26 & 33 & 9.2 \\
\hline Unknown & $\begin{array}{c}2 \\
243 \\
\end{array}$ & 0.82 & $\begin{array}{c}5 \\
117 \\
\end{array}$ & 4.27 & $\begin{array}{c}7 \\
360 \\
\end{array}$ & 1.9 \\
\hline
\end{tabular}


paydays coinciding with public holidays. ${ }^{15}$ In Reunion Island a similar trend was found for alcohol related violence. ${ }^{16}$

Over two thirds of $\mathrm{HI}$ patients were referred to PMH EC from local clinics or other hospitals, and almost two thirds of these external hospital referrals required admission. Local HI referrals, especially if self-referred or sent from clinics were discharged home over $70 \%$ of the time. In a vast, sparsely populated country such as Botswana, referral and transport of patients presents an ongoing health systems challenge. PMH referral patterns are complex as it currently serves as a primary, district hospital for Gaborone and major referral hospital for Botswana. These findings however, indicate that a high percentage of patients referred to PMH from an external hospital with a HI were correctly referred. The data also indicates that local clinics and EMS may benefit from more education on the management and referral needs of $\mathrm{HI}$ patients. National referral guidelines for $\mathrm{HI}$ are required to aim for a consistent standard of clinical care regardless of where the injury occurs; a National trauma registry is currently being proposed which would lead to further opportunities for referral studies.

\section{Limitations}

Our HI statistics only utilize hospital data, so often assault-related minor injuries are not referred or do not present to hospitals and so the number of HI from assaults can be underreported. Additionally the aetiology and demographic statistics in our study may be impacted by not including patients "brought in dead" or regional forensic data. This was a retrospective study of acute HI presentations and so further studies are required to follow patients longitudinally through hospital course and confirm discharge diagnosis, complications, and long-term morbidity.

\section{Future research}

Botswana, a landlocked upper middleincome country in Sub-Saharan Africa, provides an example of a middle-income country with tremendous opportunities to improve trauma care. Botswana has not yet developed centralized trauma services and has little epidemiological trauma data. Studies from South Africa, Botswana's largest neighbor, have documented a high incidence of assault related violence..$^{3,17}$ This study shows an almost equal proportion of HI from MVAs and assaults so further epidemiologic studies on $\mathrm{HI}$ and all trauma aetiology in Botswana would be beneficial to assist public health education, policy and resources.

Alcohol use is known to be the highest among young men worldwide, and this study highlights they are the main demographic impacted by injury here. More research on alcohol use in trauma and other risk factor profiles are required to better understand the impact of these issues on injury presentations in Botswana. Further studies regarding this and any link with pay day could also inform public health prevention campaigns, policy and appropriate hospital staffing patterns.

Young males continue to be overrepresented in this growing public health burden of HI trauma with long term financial and health implications. There is growing evidence about the long-term impact and significance of even minor head injuries. Individual responses to TBI, including minor TBI, vary considerably and some patients continue to experience neuropsychological sequelae for months or years following injury. In the immediate post-injury period, post concussive syndrome symptoms, including headaches, fatigue, dizziness, irritability, depressed mood, aggression, insomnia and cognitive processing speed reduction, can impair occupational functioning and strain interpersonal relationships. In the long-term, head trauma has been implicated in initiating or accelerating neurodegenerative processes, leading to motor and neuropsychological deterioration. ${ }^{18,19}$ Given the demographic findings, that head trauma predominantly affects young adult men, in their most productive working years, prevention of head injuries could have a significant economic and social impact.

\section{Conclusions}

This first study of acute HI in a major hospital in Botswana supports continued and expanded trauma surveillance to improve trauma knowledge, management and public health related initiatives for Head Injuries and subsequently all trauma related presentations in Botswana.

It is hoped that will assist in improving trauma surveillance, diagnostic and management strategies as well as inform public health specialists in preventative strategies and policies in trauma for Botswana and other LMICs.

\section{References}

1. Geneva WHO. Injuries and violence: the facts; 2010.

2. Krug EG, Sharma GK, Lozano R. The global burden of injuries. Am J Public Health 2000;90:523-6.
3. Jerome E, Laing GL, Bruce JL, et al. An audit of traumatic brain injury (TBI) in a busy developing-world trauma service exposes a significant deficit in resources available to manage severe TBI. S Afr Med J 2017;107:621-5.

4. Hofman K, Primack A, Keusch G, Hrynkow S. Addressing the growing burden of trauma and injury in low- and middle-income countries. Am J Public Health 2005;95:13-7.

5. Hyder AA, Wunderlich CA, Puvanachandra $P$, et al. The impact of traumatic brain injuries: a global perspective. NeuroRehab 2007;22:341-53.

6. Lagarde E. Road traffic injury is an escalating burden in Africa and deserves proportionate research efforts. PLoS Med 2007;4:6.

7. Wiebe DJ, Ray S, Maswabi T, et al. Economic development and road traffic fatalities in two neighbouring African nations. Afr J Emerg Med 2016;6:80-6.

8. Botswana Statistics. [Internet]. [cited 3rd April 2017]. Available from: http://botswana.opendataforafrica.org/p qnbol/regional-population

9. Chandra A. Epidemiology of patients presenting to the emergency centre of Princess Marina Hospital in Gaborone, Botswana. Afr J Emerg Med 2014 [Epub ahead of print].

10. Thurman DKJRC. WHO Advisory Committee on Neurotrauma Prevention. Standards Surveillance of Neurotrauma. Geneva: WHO; 1995.

11. Lofvenmark I, Norrbrink C, NilssonWikmar L, et al. Traumatic spinal cord injury in Botswana: characteristics, aetiology and mortality. Spinal Cord 2015;53:150-4.

12. Clausen T, Martinez P, Towers A, et al. Alcohol Consumption at Any Level Increases Risk of Injury Caused by Others: Data from the Study on Global AGEing and Adult Health. Subst Abuse Res Treat 2015;9:125-32.

13. Schuurman N, Cinnamon J, Walker BB, et al. Intentional injury and violence in Cape Town, South Africa: an epidemiological analysis of trauma admissions data. Global Health Action 2015;8:27016.

14. Sebego M, Naumann RB, Rudd RA, et al. The impact of alcohol and road traffic policies on crash rates in Botswana, 2004-2011: a time-series analysis. Accident Analys Prevent 2014;70:33-9.

15. Ramírez DE, Branas CC, Richmond $\mathrm{TS}$, et al. The relationship between pay day and violent death in Guatemala: a time series analysis. Injury Prevent 2017;23:102-8.

16. Vilain P, Larrieu S, Mougin-Damour K, 
et al. Emergency department syndromic surveillance to investigate the health impact and factors associated with alcohol intoxication in Reunion Island. Emerg Med J 2017;34:386-90.

17. Naidoo D. Traumatic brain injury: The
South African landscape. South Afr Med J 2013;103:613-4.

18. Daneshvar DH, Riley DO, Nowinski CJ, et al. Long-Term Consequences: Effects on Normal Development Profile After Concussion. Phys Med Rehab
Clin North Am 2011;22:683-700.

19. Hesdorffer DC, Rauch SL, Tamminga CA. Long-term psychiatric outcomes following traumatic brain injury: a review of the literature. J Head Trauma Rehab 2009;24:452-9. 